\section{Acquisition of free-operant avoidance with a response-contingent stimulus}

\author{
JAMES M. ELLIOTT and THOMAS M. KING \\ Texas A \& M University, College Station, Tex. 77843
}

Eight rats were given six $2 \cdot \mathrm{h}$ sessions on a S-S $=\mathrm{R}-\mathrm{S}=15-\mathrm{sec}$ free-operant avoidance schedule. For four $\mathrm{Ss}$, each response was immediately followed by a 0.5 -sec auditory stimulus; no exteroceptive stimulus followed responses for the other four Ss. No statistically significant differences were found between groups in terms of response rate. Ss with the response-contingent stimulus significantly reduced shock frequency over sessions. Response-contingent stimuli do influence the course of acquisition in free-operant avoidance. The possibility of the stimulus functioning as a secondary reinforcer was considered.

Free-operant avoidance, first investigated by Sidman (1953), differs from discriminated avoidance in a number of ways. In discriminated avoidance, a warning signal (CS) precedes a noxious stimulus (UCS) by an interval of time. A response during the $\mathrm{CS}$ terminates it and avoids the UCS for that trial. In free-operant avoidance, a brief inescapable shock is delivered at regular intervals as long as a response does not occur. A response delays the occurrence of the next shock for a fixed period of time. The time between shocks defines the shock-shock (S-S) interval, and the time from response to shock defines the response-shock (R-S) interval. Shock can be postponed indefinitely by a sufficiently high response rate or by a lower rate appropriately spaced in the R-S interval. In discriminated avoidance, the two-factor theory proposes that reinforcement of avoidance is escape from the conditioned aversiveness of the CS. However, in free-operant avoidance no exteroceptive stimulus change precedes or follows a response. The nature and source of reinforcement in free-operant avoidance remains elusive.

Several theoretical attempts have been made to account for reinforcement of this behavior. Sidman (1962) attributed reinforcement to a reduction in shock frequency following a response. This line of evidence was derived primarily from the relative rapidity of learning when the R-S interval is greater than the S-S interval. Anger (1963) stresses the role of conditioned aversive temporal stimuli in acquisition and maintenance. Early in training, $S$ is exposed to a large number of S-S intervals, and by classical conditioning, passage of time becomes aversive. After a number of responses have been emitted later in training, a second class of temporal stimuli become classically conditioned. These two classes of stimuli are referred to as post-shock-time (PST) and post-response-time (PRT). For Anger, the reinforcing event is a rapid reduction in aversiveness immediately following a response.

In contrast to the numerous studies of secondary reinforcement in positive reinforced behavior, little attention has been directed to response-contingent exteroceptive stimuli in free-operant avoidance. In a single 2 -h session, Bolles $\&$ Popp (1964) showed that a "click" of an empty feeder mechanism coincident with a response aided the acquisition of free-operant avoidance. With a 5-sec S-S interval and 15-sec R-S interval, 7 of $10 \mathrm{Ss}$ learned when each response was accompanied by the "click" as compared to only 2 of 10 acquiring the response when the click did not follow responses. Bolles \& Grossen (1969, Experiment 6) when a 2-sec "lights out" condition followed each response. This compared with only 3 of 9 Ss acquiring the response when the "lights out" condition did not prevail. All Ss were run in a single $3-\mathrm{h}$ session with a 5 -sec S-S interval and 30-sec R-S interval.

The present study was designed to investigate the effects of response-contingent stimuli on free-operant avoidance over an extended period of time. SUBJECTS

The Ss were eight albino male rats obtained from Ferguson Farms, Lewisville, Texas, and approximately 150 days old at the beginning of the study. Ss had not been used in previous studies and had free access to food and water in their individual home cages.

\section{APPARATUS}

A standard Lehigh Valley test chamber (Model 1316) with a single bar was used for testing all Ss. The chamber was enclosed in a ventilated sound-attenuated outer shell. Shock was generated by a Lehigh Valley shock source (Model 1531), and delivered via a grid scrambler to the gridded floor of the chamber. A series of fqund that 9 of 9 Ss acquired the response programming and recording equipment was located in an adjoining room. PROCEDURE

Equal S-S and R-S intervals of $15 \mathrm{sec}$ were used throughout the experiment for all Ss, and shock intensity was $2 \mathrm{~mA}$ for $0.5 \mathrm{sec}$. Each $\mathrm{S}$ was given a 20 -min adaptation period prior to the first $2-h$ session, and subsequent $2-h$ sessions were run on consecutive days.

Four Ss were nun under normal free-operant conditions where each response initiated a new R-S interval. A slight sound associated with the operation of the microswitch connected to the bar accompanied each response. For the other four Ss, a 0.5 -sec auditory stimulus accompanied each response. Responses occurring while the stimulus was "on" did not prolong it. In order to avoid having shock and the stimulus paired, responses during shock did not produce the auditory stimulus.

The auditory stimulus was delivered through a speaker mounted inside the outer shell. The sound was $74 \mathrm{~dB}$ of "radio static" added to a white noise background level of $68 \mathrm{~dB}$.

Some of the Ss in both groups "froze" after a few shocks in Session 1, and were administered additional shocks during the first hour of the session. Additional "shaping" was not used after the first hour of the initial session.

\section{RESULTS}

Ss typically exhibit great variability in acquisition of free-operant avoidance. This is evidenced by Fig. 1, which shows the average response rate per session for each S. An analysis of variance did not reveal a significant difference between conditions. A Mann-Whitney U test for Session 6 was

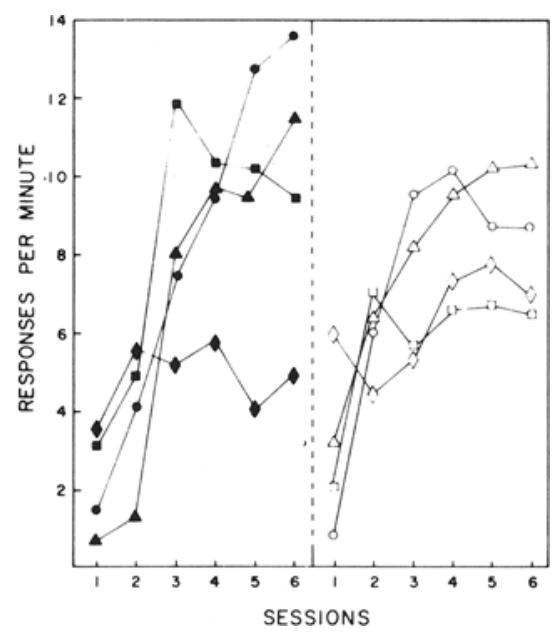

Fig. 1. Response rates per session for each $S$. Left panel is for response contingent stimulus Ss; right panel is for Ss not receiving the stimulus. 


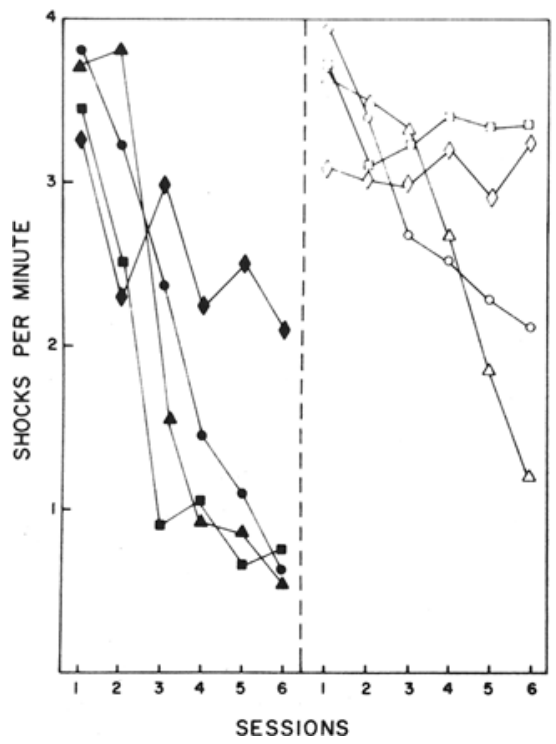

Fig. 2. Shock frequency per session for each S. Left panel is for response contingent stimulus Ss; right panel is for Ss not receiving the stimulus.

significant $(U=1, p=.057)$ when the one obvious deviate (closed diamond) was excluded. This $S$ was given seven additional sessions with little change in performance. Response rate does appear to have been facilitated by the stimulus, but this conclusion is tenuous.

The consequence of responding in a free-operant situation is a reduction in shock frequency. Figure 2 shows the average number of shocks per minute for each S. Analysis of variance did show a significant difference $(F=13.62, \mathrm{df}=1 / 6$, $\mathrm{p}<.05)$ between conditions. Reduction in shock frequency for the response-contingent stimulus $S s$ is particularly obvious for three of the Ss. The discrepancy between response rate and shock frequency is due to an imperfect inverse relation between the two measures.

\section{DISCUSSION}

It is clear that a response-contingent stimulus in free-operant avoidance has a decided influence on the acquisition of free-operant avoidance. However, theoretical interpretation of the results of this study is equivocal. In positive reinforced behavior, pairing a neutral stimulus with a response and reinforcer is the paradigm for establishing the neutral stimulus as a secondary reinforcer. With the exception of a clearly defined primary reinforcer, the procedures of this study are analogous to procedures for producing secondary reinforcement. The reinforcing event associated with a response in free-operant avoidance is not apparent, but Anger's (1963) conditioned aversive temporal-stimuli hypothesis does propose a plausible reinforcer. Reinforcement stems from a reduction in aversiveness following a response, and aversiveness again increases to a peak immediately prior to the next scheduled shock. Consequently, pairing a neutral stimulus with a reduction in aversiveness might be expected to establish the neutral stimulus as a secondary reinforcer. According to Kimble (1961), stimuli associated with the termination of "pain" may acquire positive reinforcing properties. This idea has not been systematically investigated, but the acceleration in response rate for $S s$ in response-contingent stimulus group may be partially explained by this formulation. The Anger hypothesis, on the other hand, would predict a lower response rate that would more closely match the requirement dictated by the length of the R-S interval. However, clear temporal discrimination may appear only after much extended training. The results of this exploratory study do show that a response-contingent stimulus influences the course of acquisition in free-operant avoidance. Since the response-contingent stimulus was superimposed on the normal course of acquisition, it is difficult to ascertain the function of the stimulus. Thus the exact nature and extent of stimuli correlated with responses in free-operant avoidance must await further investigation.

\section{REFERENCES}

ANGER, D. The role of temporal discrimination in the reinforcement of Sidman avoidance behavior. Journal of the Experimental Analy sis of Behavior, 1963, 6, 477-506.

BOLLES, R. C., \& POPP, R. J., JR. Parameters affecting the acquisition of Sidman avoidance. Joumal of the Experimental Analysis of Behavior, 1964, 7, 315-321.

BOLLES, R. C., \& GROSSEN, N. E. Effects of an informational stimulus on the acquisition of avoidance behavior in rats. Journal of Comparative \& Physiological Psychology, $1969,68,90-99$.

KIMBLE, G. A. Hilgard and Marquis' Conditioning and learning. New York: Appleton-Century-Crofts, 1961.

SIDMAN, M. Avoidance conditioning with brief shock and no exteroceptive warning signal. Science, 1953, 118, 157-158.

SIDMAN, M. Reduction of shock frequency as reinforcement for avoidance behavior. Journal of the Experimental Analysis of Behavior, $1962,5,247-257$

\section{Retention of avoidance running ${ }^{1}$}

ROBERT S. BEECROFT, University of North Dakota, Grand Forks, N. Dak. 58201 , and BONNIE G. FISHER, University of Iowa, Iowa City, Iowa 52240

Resistance to extinction of avoidance running was studied at four retention intervals. Resistance to extinction decreased from $1 \mathrm{~min}$ to $4 \mathrm{~h}$, held steady at $24 \mathrm{~h}$, then decreased again to $144 \mathrm{~h}$. Running times increased for the delayed-retention $S s$

In this experiment a rat is trained to run from the startbox through a 6 -ft alley to the goalbox in less than $3 \mathrm{sec}$, thereby avoiding the shock that accompanies slower runs. After this single avoidance run, simple extinction without shock begins on the next trial after retention intervals varying from $1 \mathrm{~min}$ to $144 \mathrm{~h}$. Thus, this is a retention study using a resistance to extinction criterion. The limited amount of acquisition training should be noted. However, our previous studies indicate that training Ss to the criterion of three successive avoidances (Beecroft, 1967) or giving 10 training trials beyond the first avoidance (Beecroft, Fisher, \& Bouska, 1967, Experiment 1) does not materially increase resistance to extinction. Also, we were interested in determining if the Kamin effect (Kamin, 1957) would appear in extinction data; there is some evidence that the Kamin effect is most conspicuous when initial avoidance training is limited (Anderson, Johnson, Schwendiman, \& Dunford, 1966).

\section{METHOD}

The runway consisted of a duplex startbox, a 6-ft alley, and a large black goalbox (cf. Brown, Martin, \& Morrow, 1964, for details). All rats were trained to 